\title{
Prevalence and severity levels of post-radical prostatectomy incontinence: different assessment instruments
}

\author{
Prevalência e níveis de gravidade de incontinência urinária pós-prostatectomia radical: \\ diferentes instrumentos de avaliação \\ Prevalencia y niveles de severidad de la incontinencia urinaria pos-prostatectomía radical: \\ diferentes instrumentos de evaluación
}

Luciana Regina Ferreira da Mata' ORCID: 0000-0002-5080-4643

Cissa Azevedo' ORCID: 0000-0001-5881-5710

Lívia Cristina de Resende Izidoro" ORCID: 0000-0002-4999-1752

Darkiane Fernandes Ferreira' ORCID: 0000-0001-9191-6126

Fabrícia Eduarda Baia Estevam' ORCID: 0000-0002-0677-5726

Fabrícia Moreira Amorim Amaral"I ORCID: 0000-0003-4765-0062

Tânia Couto Machado Chianca' ORCID: 0000-0002-8313-2791

'Universidade Federal de Minas Gerais. Belo Horizonte, Minas Gerais, Brazil.

"Universidade Federal de Goiás. Goiânia, Goiás, Brazil. "'Universidade Federal de São João Del-Rei. Divinópolis,

Minas Gerais, Brazil.

How to cite this article: Mata LRF, Azevedo C, Izidoro LCR, Ferreira DF, Estevam FEB, Amaral FMA, et al. Prevalence and severity levels of postradical prostatectomy incontinence: different assessment instruments. Rev Bras Enferm. 2021;74(2):e20200692. https://doi.org/10.1590/0034-7167-2020-0692

\section{Corresponding author:} Luciana Regina Ferreira da Mata E-mail: lucianarfmata@gmail.com

EDITOR IN CHIEF: Antonio José de Almeida Filho ASSOCIATE EDITOR: Álvaro Sousa

Submission: $07-15-2020$

Approval: $10-09-2020$

\begin{abstract}
Objectives: to analyze urinary incontinence prevalence and severity in prostatectomized men assessed by three different instruments. Methods: a cross-sectional study was conducted with 152 men. The pad test, pad used, and International Consultation on Incontinence Questionnaire - Short Form (self-report) were considered. Data were analyzed using Spearman's correlation, Kappa index, considering a significance level of 0.05 . Results: urinary incontinence prevalence was $41.4 \%, 46.7 \%$ and $80.3 \%$ according to pad used, pad test and self-report. Positive correlations and moderate to poor agreement were found between the instruments. As for severity, most participants had mild incontinence. The largest number of cases of mild and severe incontinence was identified by self-report. Conclusions: the selfreport showed higher values for prevalence of mild and severe severity levels. Through the identified differences, we propose that the objective assessment (pad used and pad test) be associated with individuals' perception (self-report) to better estimate prevalence and severity. Descriptors: Urinary Incontinence; Prostatectomy; Evaluation Study; Prostatic Neoplasms; Nursing Care.
\end{abstract}

\section{RESUMO}

Objetivos: analisar a prevalência e a gravidade da incontinência urinária em homens prostatectomizados a partir de três instrumentos diferentes. Métodos: estudo transversal, realizado com 152 homens. Foram considerados os instrumentos pad test, pad used e International Consultation on Incontinence Questionnaire - Short Form (autorrelato). Os dados foram analisados por correlação Spearman, Índice Kappa, considerando nível de significância 0,05. Resultados: a prevalência de incontinência urinária foi $41,4 \%, 46,7 \%$ e $80,3 \%$ segundo pad used, pad test e autorrelato, respectivamente. Constataram-se correlações positivas e concordâncias de moderada a pobre entre os instrumentos. Quanto à gravidade, a maioria dos participantes apresentou incontinência leve. O maior número de casos de incontinência leve e severa foi identificado pelo autorrelato. Conclusões: o autorrelato apontou valores superiores para prevalência e níveis de gravidade leve e severa. Mediante as diferenças identificadas, propomos que a avaliação objetiva (pad used e pad test) seja associada à percepção do indivíduo (autorrelato) para melhor estimativa da prevalência e gravidade. Descritores: Incontinência Urinária; Prostatectomia; Estudos de Avaliação; Neoplasias da Próstata; Cuidados de Enfermagem.

\section{RESUMEN}

Objetivos: analizar la prevalencia y la severidad de la incontinencia urinaria en hombres prostatectomizados a partir de tres instrumentos diferentes. Métodos: estudio transversal, realizado con 152 hombres. Los instrumentos considerados fueron el pad test, pad used y International Consultation on Incontinence Questionnaire - Short Form (autoinforme). Los datos fueron analizados mediante correlación de Spearman, índice Kappa, considerando un nivel de significancia de 0.05 . Resultados: la prevalencia de incontinencia urinaria fue del $41,4 \%$, $46,7 \%$ y $80,3 \%$ según pad used, pad test y autoinforme, respectivamente. Se encontraron correlaciones positivas y concordancia moderada a pobre entre los instrumentos. En cuanto a la gravedad, la mayoría de los participantes presentaba incontinencia leve. El mayor número de casos de incontinencia leve y grave se identificó mediante autoinforme. Conclusiones: el autoinforme mostró mayores valores de prevalencia y niveles de gravedad leve y grave. Mediante las diferencias identificadas, proponemos que la evaluación objetiva (pad used y pad test) se asocie con la percepción del individuo (autoinforme) para estimar mejor la prevalencia y severidade.

Descriptores: Incontinencia Urinaria; Prostatectomía; Estudio de Evaluación; Neoplasias de la Próstata; Atención de Enfermería. 


\section{INTRODUCTION}

Although the advance in prostate cancer (PC) control is growing, it is still a public health concern worldwide, being responsible for the second leading cause of cancer death among men ${ }^{(1-2)}$. Estimates indicate that the highest incidence rates are found in Australia, New Zealand and European countries in northern and eastern regions ${ }^{(2)}$. In Brazil, 65,840 new cases of PC are expected for each year of the 2020-2022 triennium, which corresponds to a risk of 62.95 new cases for every 100 thousand men $^{(3)}$.

Among the various treatment modalities for $\mathrm{PC}$, the main strategy considered the gold standard for localized PC is radical prostatectomy (RP). Surgery is based on the surgical removal of the prostate gland, seminal vesicles, part of the vas deferens and, in many cases, the bladder neck ${ }^{(4)}$. However, although RP contributes to longer survival, a possible side effect and common after surgery is urinary incontinence (UI), which can significantly compromise quality of life ${ }^{(5)}$.

The International Continence Society (ICS) defines UI as a complaint of any $\mathrm{UI}$ or involuntary outflow ${ }^{(6)}$. All forms of $\mathrm{UI}$ are caused by bladder, sphincter dysfunction or a combination of both. In prostatectomized patients, two main types are distinguished: effort (70\%) and urgency (30\%) $\mathrm{UI}^{(7)}$. Stress $\mathrm{UI}$ is the involuntary $\mathrm{UI}$ after performing activities that increase intra-abdominal pressure; urgency $\mathrm{UI}$ is the involuntary $\mathrm{UI}$ that occurs immediately after a strong urge to urinate ${ }^{(6,8)}$.

It is observed that the majority of patients submitted to RP manifest $\mathrm{UI}$ in the early postoperative period, immediately after indwelling bladder catheter (IBC) removal, which usually happens between four and 20 days after surgery ${ }^{(9)}$. The rehabilitation of urinary continence is gradual and according to the ICS it is estimated that within one month after surgery, $80 \%$ of men experience post-radical prostatectomy incontinence (PRPI) ${ }^{(10)}$. Another relevant data points out that despite the spontaneous decrease in $\mathrm{Ul}$ at two years postoperatively, $22 \%$ of men can use an absorbent a day and $22 \%$ more than an absorbent a day ${ }^{(6)}$.

The ICS recommends that for the assessment of an incontinent person it is important to specify Ul circumstances, frequency, and severity ${ }^{(6)}$. Thus, it is necessary to have specific parameters that assess both UI characteristics and severity ${ }^{(11)}$. An approach based on the investigation of clinical variables and lifestyle habits related to voiding dysfunction can support the development of strategies aimed at minimizing or resolving them.

Among the methods of simple, non-invasive and effective measures to assess $\mathrm{UI}$ presence and severity, one can mention the pad test and the pad used ${ }^{(6)}$. The pad test has been recommended by the ICS since 1988 , being a standardized way of measuring UI(6). There are different versions of this test according to the duration; however, the one-hour test has been adopted in clinical practice, since the longer the application time, the greater the infeasibility to implement it ${ }^{(12)}$. The pad used is widely used for its simplicity, and consists of questioning the number of changes in the pad/ liner/diaper in a 24 -hour period ${ }^{(13)}$.

Since 1997, the ICS recommends that measures related to quality of life be included in all clinical research on $\mathrm{Ul}$ as an additional complement to traditional clinical parameters ${ }^{(6)}$. Thus, in addition to instruments such as those mentioned, there are also validated questionnaires ${ }^{(14-15)}$, which consist of precise measures on patients' perception of UI. In this context, the International Consultation on Incontinence Questionnaire - Short Form (ICIQ-SF) provides a brief and general assessment allowing, in addition to detecting $\mathrm{Ul}$, the measurement of its severity and its impact on quality of life ${ }^{(15)}$.

It is known that the estimated prevalence of PRPI is between eight and $87 \%(6,10)$, which characterizes a high variability. The different strategies for measuring this outcome may result in this variability in prevalence rates $s^{(6)}$. Therefore, it is important to recognize that subjective and objective methods have different sensitivity for assessing the same clinical condition, in this case $\mathrm{UI}^{\left({ }^{16)}\right.}$. Thus, this study is relevant for comparing UI measurement instruments, in order to answer the following questions: is there a relationship and agreement between the prevalence measures assessed by the pad test, pad used, and ICIQ-SF? How are the distributions of UI severity levels across these three assessment instruments?

\section{OBJECTIVES}

To analyze urinary incontinence prevalence and severity in prostatectomized men assessed by three different instruments.

\section{METHODS}

\section{Ethical aspects}

In compliance with the recommendations of Resolution 466/12 of the Brazilain National Health Council (Conselho Nacional de Saúde) regarding research related to human beings, the study was assessed and approved for implementation by the Research Ethics Committee of Universidade Federal de São João del-Rei. Data collection started by signing the Informed Consent Form (ICF), leaving a copy with participants.

\section{Design, period, place of study}

This is a cross-sectional study described from the guidelines for observational studies (Strengthening the Reporting of Observational Studies in Epidemiology - STROBE) ${ }^{(17)}$. It was carried out from August 2017 to June 2018. The sample consisted of men submitted to RP in a High Complexity Care Unit in Oncology (UNACON - Unidade de Assistência de Alta Complexidade em Oncologia) in Minas Gerais, linked to the Brazilian National Cancer Institute (INCA - Instituto Nacional do Câncer).

\section{Sample; inclusion and exclusion criteria}

The sample size calculation was defined using the statistical test of simple random sample for finite population ${ }^{(18)}$, estimating a proportion of $\mathrm{Ul}$ referring to the population of interest equal to $46.7 \%{ }^{(19)}$. Thus, considering the population of men treated at the institution in a two-year interval equivalent to 242 individuals, with a margin of error of $5 \%$ and a confidence level of $95 \%$, the calculation resulted in a minimum size of 149 participants.

Men aged over 18 years who underwent RP in postoperative follow-up for at least two months and maximum two years were selected, with preserved auditory and verbal capacity. Those who were using an IBC and those who reported preoperative UI were excluded. 


\section{Study protocol}

An invitation to participate in the study was carried out on the medical return day, with presentation of the research objectives and the interview procedures. All men who agreed to participate completed the ICF. Data collection was carried out through an individual interview conducted by one of the researchers before the medical consultation, in a nursing room, in a private environment.

The data collection instruments used were: sociodemographic questionnaire, ICIQ-SF ${ }^{(15)}$, and the clinical tests used pad $^{(13)}$ and one-hour pad test ${ }^{(12)}$.

For sociodemographic and clinical characterization, an instrument was elaborated that included data such as age, education, individual monthly income, professional and marital status, type of surgery (retropubic or laparoscopic), and post-surgery time.

The ICIQ-SF consists of a simple, short and self-administered instrument that assesses the impact of UI on quality of life and qualifies patients' UI. It consists of four questions related to UI frequency, severity, impact and self-diagnosis related to the causes or situations of UI experienced, respectively ${ }^{(15)}$. The total score ranges from zero to 21 , and the higher the value, the greater the impact on quality of life. In the present study, items three and four of the ICIQ-SF were considered, for analysis purposes, since they are the items of the instrument related to UI frequency and quantity, i.e., they allow to establish, specifically, UI prevalence and its severity. It is noteworthy that participants were instructed to answer the items based on their current clinical condition with regard to UI.

Item three of the ICIQ-SF (How often do you lose urine?) aims to assess $\mathrm{UI}$ prevalence ${ }^{(15)}$. Answers range from zero to five, with zero - never; one - once a week or less; two - two or three times a week; three - once a day; four- several times a day; five - all the time ${ }^{(15)}$. Thus, individuals who reported no involuntary UI (ever) are classified as continents and those who reported any involuntary $\mathrm{UI}$, regardless of frequency, should be classified as incontinent ${ }^{(6)}$. Item four of the ICIQ-SF (We would like to know how much urine you think you lose) consists of analyzing UI severity ${ }^{(15)}$. Answers range from zero to six, with zero meaning no loss (continent), two - a small amount (mild UI), three - a moderate amount (moderate $\mathrm{UI}$ ) and six - a large amount (severe $\mathrm{UI})^{(15)}$.

The pad used aims to quantify the number of pads used by the individual in 24 hours. Thus, $\mathrm{Ul}$ is classified as mild (when absorbent use is one to two per day), moderate (three to five absorbents per day) and severe (more than six absorbents per day). Men who used no pads were classified as continents ${ }^{(13)}$.

The one-hour pad test consists of placing a penile pad close to the external urethral meatus to quantify UI by comparing the weight of this pad before and after the hour. During this interval, patients are submitted to a protocol of fluid intake and Activities of Daily Living ${ }^{(6,12)}$. From the difference in weight of the initial and final absorbent, Uls are classified as: insignificant or continent loss (when the final weight of the absorbent is up to one gram (g), slight loss (1.1 to $9.9 \mathrm{~g}$ ), moderate loss (10 to $49.9 \mathrm{~g}$ ) and severe loss (above 50 $\mathrm{g})^{(12)}$. At the beginning of data collection, patients were instructed on the positioning of the absorbent and to place it at that moment of the interview. Then, $500 \mathrm{~mL}$ of water were offered and the activities protocol that should be carried out in an hour was explained.
During the initial 15 to 20 -minute interval, according to the pad test protocol, patients should remain at rest; therefore, at this time, the other data collection instruments were applied (sociodemographic questionnaire, ICIQ-SF and pad used). Subsequently, a script of activities was carried out which included: walking in slow steps, sitting and standing, picking up objects on the floor, coughing, washing hands under running water, going up and down stairs. These activities were carried out on the institution's premises. After the activities were completed, the patient was returned to the nursing room, where a plastic bag was offered to discard the absorbent. Finally, the researcher used a precision scale to measure the weight of the absorbent and complete the test result.

\section{Analysis of results, and statistics}

Data were processed and analyzed using the Statistical Package for Social Science (SPSS), version 21.0 for Windows. The ShapiroWilk test was applied to test the normality of explanatory variables. The results obtained for explanatory variables (sociodemographic characterization) were analyzed using descriptive statistics with measures of central tendency (mean or median) and variability (standard deviation or interquartile range) for continuous variables, and relative frequency for variables categorical.

PRPI prevalence with the respective $95 \%$ confidence interval (confidence interval - $95 \% \mathrm{Cl}$ ) was calculated from the findings of the pad test, pad used and item three on the ICIQ-SF scale.

In order to identify possible relationships between the levels of PRPI assessed by the pad test, pad used and items three and four of the ICIQ-SF, Spearman's correlation test was used. The correlation forces were analyzed considering values between 0.10 and 0.39 as of low magnitude, between 0.40 and 0.69 of moderate magnitude and above 0.70 of strong magnitude ${ }^{(20)}$.

Then, agreement analysis was performed between PRPI occurrence according to each of the three instruments (pad test, pad used and item three of the ICIQ-SF) using Kappa coefficient with the respective $95 \% \mathrm{Cl}$. Agreement was analyzed from the parameters: null $(k=0)$, poor $(0.01-0.19)$, weak $(0.20-0.39)$, moderate (0.40 - 0.59), substantial $(0.60-0.79)$ and almost perfect $(0.80-1)$ (21). In all analyzes, a significance level of 0.05 was considered.

Histograms were designed to compare the distribution of PRPI severity levels (continent, mild, moderate and severe) according to the three instruments.

\section{RESULTS}

The number of participants eligible for the study was 175 men. However, 15 individuals were disregarded due to IBC use, five who reported previous UI and three who did not accept to participate in the study. Therefore, the sample consisted of 152 men. The median age was 67 (62-72.7) years. As for education, participants had a median of four (2-4) years of study. The median individual monthly income was 937 (937-1405) reais (reais is the Brazilian currency). Concerning professional situation, $78.9 \%$ were inactive (retired or unemployed) and $80.3 \%$ had a partner. Most performed the surgery using the retropubic technique (97.4\%) and the post-surgery time varied between 60 and 730 days, with a median of 209 days, i.e., approximately seven months. 
PRPI prevalence was $46.7 \%(\mathrm{Cl}=38.7 \% ; 54.7 \%)$ according to the pad test, $41.4 \%(\mathrm{Cl}=33.5 \% ; 49.4 \%)$ by the pad used and $80.3 \%$ $(\mathrm{Cl}=73.9 \% ; 86.7 \%)$ by item three of the ICIQ-SF.

When analyzing possible correlations between the levels of PRPI by the three assessment methods, a positive correlation of moderate magnitude was found between pad test and pad used $(r=0.54 / p$ $<0.001)$, and pad used and item three of ICIQ- SF $(r=0.61 / p<0.001)$. There was also a positive correlation of weak magnitude between the pad test and item three of the ICIQ-SF $(r=0.37 / p<0.001)$.

Concerning the agreement between the three instruments for PRPI prevalence assessment, moderate agreement was identified between pad test and pad used, poor between pad test and item three of the ICIQ-SF, and weak between pad used and item three of the ICIQ-SF (Table 1).

Table 1 - Agreement between the pad test, pad used and item three instruments of the International Consultation on Incontinence Questionnaire - Short Form regarding urinary incontinence prevalence assessment, Divinópolis, Minas Gerais, Brazil, 2018, $(n=152)$

\begin{tabular}{lcccc}
\hline $\begin{array}{l}\text { Assessment } \\
\text { methods }\end{array}$ & Kappa & $\mathbf{9 5 \%} \mathbf{C l}^{\ddagger}$ & $\boldsymbol{p}$ & Agreement \\
\hline Pad used and pad test & 0.441 & {$[0.297 ; 0.585]$} & $<0.001^{\dagger}$ & Moderate \\
$\begin{array}{l}\text { Item three of the } \\
\text { ICIQ-SF* and pad test }\end{array}$ & 0.076 & {$[0.000 ; 0.229]$} & 0.218 & Poor \\
$\begin{array}{l}\text { Item three of the } \\
\text { ICIQ-SF* and pad used }\end{array}$ & 0.297 & {$[0.156 ; 0.437]$} & $<0.001^{\dagger}$ & Weak \\
\hline
\end{tabular}

Note: *International Consultation on Incontinence Questionnaire - Short Form; ${ }^{+} p<0.05 ;{ }^{*} 95 \%$ Confidence Interval.

The distribution of participants according to PRPI levels of severity (continent, mild, moderate, and severe) by the three assessment methods is shown in Figure 1. The difference in the distribution of participants assessed by ICIQ-SF stands out for the classification continent $(n=30)$ and "mild" PRPI $(n=99)$ in relation to the other methods. With this finding, it appears that in the severity assessment by self-report there was a predominance of complaints of loss of a small amount of urine. In the "severe" PRPI classification, self-report (ICIQ-SF) was an instrument that identified a greater number of participants $(n=10)$ in this category.

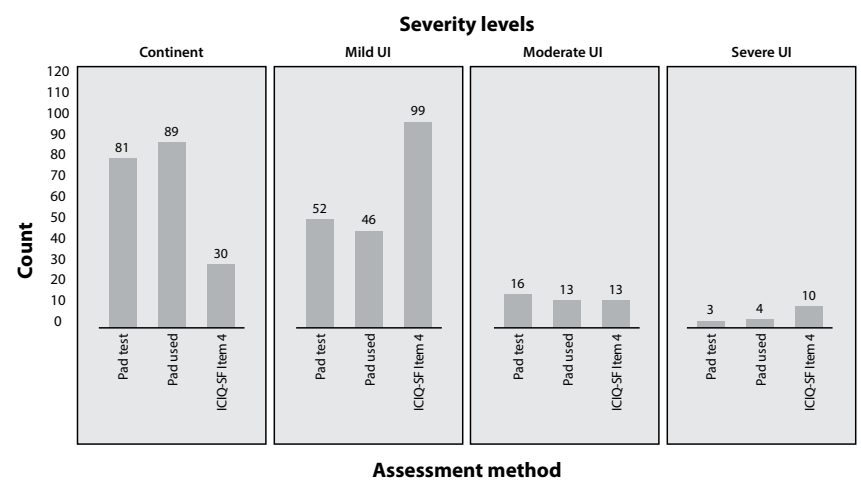

Note: UI - Urinary incontinence; ICIQ-SF - International Consultation on Incontinence Questionnaire - Short Form.

Figure 1 - Distribution of participants according to level of severity of urinary incontinence (continents, mild, moderate and severe) according to the pad test, pad used and item four of the International Consultation on Incontinence Questionnaire - Short Form, Divinópolis, Minas Gerais, Brazil, 2018

\section{DISCUSSION}

The results of this study allowed us to show the variability in PRPI prevalence and levels of severity before different assessment strategies. For this sample, we estimated a prevalence of PRPI of $46.7 \%$ according to the pad test, $41.4 \%$ according to the pad used and $80.3 \%$ according to item three of the ICIQ-SF. Thus, the prevalence measured by item three of the ICIQ-SF was considerably higher than the prevalence assessed by the pad used and pad test. This finding corroborates the results of research carried out in recent years on methods of assessing UI that highlighted the greater or lesser validity of one method in relation to the other ${ }^{(5,16,22-23)}$.

A research carried out in Norway ${ }^{(16)}$ identified a $74 \%$ prevalence of PRPI after one year of surgery when assessing UI by reporting on the perception of "any involuntary $\mathrm{UI}^{\prime \prime(6)}$ and $40 \%$ according to the pad used (use of at least one absorbent/liner/diaper per day). The authors stressed that this discrepancy can be attributed to the discomfort felt by individuals when they perceive involuntary Ul, even if this loss is minimal(16).

In Spain, scholars have assessed the prevalence of PRPI in 172 men one year after surgery, considering UI as any involuntary $\mathrm{UI}^{(6)}$ and identified a prevalence of $23 \%$. They also found that $17.8 \%$ used at least one absorbent/day and $11.9 \%$ more than one absorbent/day ${ }^{(5)}$.

In a study ${ }^{(22)}$ carried out in Japan with men after a year of RP, a prevalence of PRPI of 75\% was identified by the ICIQ-SF, 33\% by the pad used and $36 \%$ by the 24 -hour pad test. The authors stressed that no method should prevail over the others, and a broad clinical assessment is essential, in addition to considering that the best option will always be the one that can be measured and compared in the pre and postoperative period, whatever this may be ${ }^{(22)}$. We believe that the differences in prevalence identified in the self-report assessment (ICIQ-SF) in relation to the two objective assessments (pad used and pad test) reinforce the idea that the assessments are complementary for the selection of PRPI control interventions that includes since change in lifestyle and pelvic muscle training for drug or surgical interventions ${ }^{(6)}$.

Australian scholars have also identified a discrepancy between the subjective impression of prostatectomized patients on continence status and objective criteria. It was found that $34.4 \%$ of the 479 men submitted to RP were classified as incontinent through a telephone interview that asked "do you have involuntary UI?", While only $14.9 \%$ of these men were classified as incontinent through the 24 -hour pad test ${ }^{(23)}$. The experience regarding UI may present different interpretations due to the questioning itself, whose focus may be on use or not of an absorbent or the amount of UI itself ${ }^{(24)}$.

There are also situations in which, although patients experience UI several times a day, they are resistant to using the absorbent because they consider the amount lost to be very small. Thus, we suggest that the amount of $\mathrm{Ul}$ is what determines use or not of an absorbent and not the frequency of this loss ${ }^{(25)}$.

The number of absorbents in 24 hours is an important aspect for determining UI; however, this does not accurately define Ul, other complementary information such as the size and frequency of changing the absorbent, the absorption capacity of 
that absorbent, and the moisture tolerance of each individual being important ${ }^{(26)}$. Another relevant data refers to the shape of the absorbent, as individuals who use rectangular pads are $40 \%$ more likely to change the device more frequently in a 24-hour period when compared to those who use diaper-type pads ${ }^{(27)}$.

Regarding the definition of UI through the number of pads or diapers used, authors have used in their studies the criterion that continent individuals are those who do not use pads or use them only for safety ${ }^{(28-29)}$, which is also accepted by the ICS ${ }^{(6)}$. In contrast, there are scholars who consider it more appropriate and objective to define individuals as continents when they do not use any absorbent/liner/diaper ${ }^{(13,30)}$. We understand, therefore, that the existence of different definitions can also impact the fluctuation in the prevalence rates of PRPI.

The results also showed positive correlations between the assessment methods, i.e., an increase in the amount of Ul increased the number of absorbents used, as well as individuals' perceptions of UI frequency. Other studies that assessed the correlation between different methods also identified a positive relationship between them, with a predominance of weak to moderate correlation forces ${ }^{(22,31-32)}$.

As for agreement between instruments, assessed using Cohen's Kappa coefficient, there was significant agreement between assessment by the pad test and pad used, as well as by the pad used and item three of the ICIQ-SF, with stronger agreement between pad used and pad test. This finding can be justified by the fact that both are objective methods of assessing UI that do not involve man's perceptions of the frequency of this loss ${ }^{(6)}$.

In a study that assessed agreement between the one-hour pad test and the ICIQ-SF, a weak agreement (kappa <0.34) was identified between the methods ${ }^{(33)}$. Although the one-hour pad test has the advantage of a greater chance of adherence by patients ${ }^{(34)}$, factors such as level of physical effort, use of drugs such as antibiotics and antidiuretics, and low daily water intake can impact the results. These factors can interfere with the real frequency of UI and, consequently, with the severity and impact of UI on patients' quality of life ${ }^{(35)}$.

A research carried out in Germany, which assessed the agreement between pad used and self-report of involuntary UI, showed an agreement of $0.73,0.70$ and 0.64 at three, six and 12 months after surgery, respectively ${ }^{(30)}$. The greater agreement identified in this study can be justified by the definition adopted for the self-report of involuntary UI. Individuals were considered as continent if they did not use any type of device ${ }^{(30)}$.

As for comparison of the distribution of Ul severity between the three assessment strategies, it is realized that by self-report (ICIQSF), most participants were classified as "mild" PRPI. In contrast, severity assessment by the pad test and pad used pointed out that most participants were continents. Moreover, in the "severe" PRPI classification, self-reporting also stood out with the largest number of participants. These findings reinforce the idea that men's perceptions of UI have a greater impact on the degree of severity compared to severity assessment by measuring the volume of Ul and the number of absorbents used. Furthermore, it shows us that subjective assessment is important and complementary(22) and directs nursing actions within the scope of self-perception, coping, and adaptation to health conditions.

\section{Study limitations}

As a limitation of this study, we evidenced the recruitment of participants in a single institution, which increases the chances of a sample with very similar characteristics in relation to income and education, which can impact hygiene conditions and, consequently, the frequency of changing absorbents. Another limiting factor that we identified is related to the pad test application, since older men had limitations to perform all the daily activities contemplated in the protocol, which made it difficult to standardize the level of physical effort among participants.

\section{Contributions to nursing}

We know that the differences between prevalence values of PRPI in clinical practice reinforce the importance of the knowledge we need to select assessment instruments, in addition to highlighting the need for new studies that propose specific questionnaires for the male audience.

Ul assessment by nurses is an important parameter for planning care. In the case of patients in outpatient care, the severity of this symptom indicates the need for more frequent follow-up, either by telephone contact or home visits. In more complex situations, the possibility of surgical or drug intervention can be discussed with the medical team.

Knowing the specificities of $\mathrm{UI}$ measurement instruments favors the professional improvement of nurses in the area of voiding dysfunctions. It is important to understand that nursing is considered the driving force of the health team and is therefore able to change the reality of care related to UI control in the Brazilian health system.

\section{CONCLUSIONS}

The present study compared PRPI prevalence and severity levels under three different methods, two objectives (pad test and pad used) and one subjective (ICIQ-SF - self-report). We found a higher prevalence of PRPI by the subjective method. As for level of severity, most participants had a mild UI in an assessment using the three instruments. Among the cases of mild and severe UI, self-report assessment showed the largest number of individuals for these classifications.

It is noticed, therefore, that the self-report pointed higher values for prevalence and mild and severe levels. Thus, lower rates indicated by the one-hour pad test and the pad used suggest that such methods are less reliable when assessed in isolation to estimate PRPI prevalence and severity, without considering the perception of individuals who present involuntary UI. Through this difference identified between the instruments, we propose that the objective assessment is associated with the perception of individuals, since the same amount of UI can be perceived differently among men, considering their personal and social perceptions.

Finally, due to the variability in PRPI rates by the methods analyzed and the difficulty in establishing the real magnitude of this involvement, we emphasize the importance of future investigations with proposals for a single instrument that associates objective and subjective data to determine UI prevalence and severity within the male population. 


\section{FUNDING}

National Council for Scientific and Technological Development - (Process number 429958/2018-8).
Coordination for the Improvement of Higher Education Personnel - Brazil - Financing Code 001.

Minas Gerais State Research Support Foundation (APQ -03583-18).

\section{REFERENCES}

1. Araújo JS, Zago MMF. Masculinities of prostate cancer survivors: a qualitative metasynthesis. Rev Bras Enferm. 2019;72(1):240-9. https://doi. org/10.1590/0034-7167-2017-0730

2. Ferlay J, Colombet M, Soerjomataram I, Mathers C, Parkin DM, Pineros M, et al. Estimating the global cancer incidence and mortality in 2018: GLOBOCAN sources and methods. Int J Cancer. 2019;144(8):1941-53. https://doi.org/10.1002/ijc.31937

3. Ministério da Saúde (BR). Estimate 2020: cancer incidence in Brazil. Rio de Janeiro: INCA; 2019. 122 p. [cited 2020 Jul 14]. Available from: https://www.inca.gov.br/sites/ufu.sti.inca.local/files//media/document//estimativa-2020-incidencia-de-cancer-no-brasil.pdf

4. Butler SS, Mahal BA, Lamba N, Mossanen M, Martin NE, Mouw KW, et al. Use and early mortality outcomes of active surveillance in patients with intermediate-risk prostate cancer. Cancer. 2019;125(18):3164-71. https://doi.org/10.1002/cncr.32202

5. Tienza A, Robles JE, Hevia M, Algarra R, Diez-Caballero F, Pascual Jl. Prevalence analysis of urinary incontinence after radical prostatectomy and influential preoperative factors in a single institution. Aging Male. 2018;21(1):24-30. https://doi.org/10.1080/13685538.2017.1369944

6. Abrams P, Cardozo L, Wagg A, Wein A. Incontinence. 6 th Edition. Bristol: United Kingdom; 2017. 2619 p.

7. Sandhu JS, Breyer B, Comiter C, Eastham JA, Gomez C, Kirages DJ, et al. Incontinence after Prostate Treatment: AUA/SUFU Guideline. J Urol. 2019;202(2):369-78. https://doi.org/10.1097/JU.0000000000000314

8. Costa JN, Lopes MVO, Lopes MHBM. Simultaneous concept analysis of diagnoses related to urinary incontinence. Int J Nurs Knowl. 2019;0(0):1-15. https://doi.org/10.1111/2047-3095.12254

9. Tilki D, Preisser F, KaraKieWicz P, Shariat SF, Graefen M, Huland H, et al. The impact of time to catheter removal on short, intermediate and long-term urinary continence after radical prostatectomy. World J Urol. 2018;36(8):1247-53. https://doi.org/10.1007/s00345-018-2274-y

10. Arroyo C, Martini A, Wang J, Tewari AK. Anatomical, surgical and technical factors influencing continence after radical prostatectomy. Ther Adv Urol. 2019;11:1756287218813787. https://doi.org/10.1177/1756287218813787

11. Hester AG, Kretschmer A, Badlani G. Male Incontinence: the etiology or basis of treatment. Eur Urol Focus. 2017;3(4-5):377-84. https://doi. org/10.1016/j.euf.2017.12.002

12. Krhut J, Zachoval R, Smith PP, Rosier PF, Valanský L, Martan A, et al. Pad weight testing in the evaluation of urinary incontinence. Neurourol Urodyn. 2014;33(5):507-10. https://doi.org/10.1002/nau.22436

13. Angulo JC, Cruz F, Esquinas C, Arance I, Manso M, Rodríguez A, et al. Treatment of male stress urinary incontinence with the adjustable transobturator male system: outcomes of a multi-center Iberian study. Neurourol Urodyn. 2017;37(4):1458-66. https://doi.org/10.1002/ nau.23474

14. Tamanini JTN, D'Ancona CAL, Botega NJ, Netto NR. Validation of the Portuguese version of the King's Health Questionnaire for urinary incontinent women. Rev Saúde Pública. 2003;37(2):203-11. https://doi.org/10.1590/S0034-89102003000200007

15. Tamanini JTN, Dambros M, D'Ancona CAL, Palma PCR, Netto NR. Validation of the "International Consultation on Incontinence Questionnaire - Short Form" (ICIQ-SF) for Portuguese. Rev Saúde Pública. 2004;38(3):438-44. https://doi.org/10.1590/S0034-89102004000300015

16. Holm HV, Fossa SD, Hedlund H, Schultz A, Dahl AA. How should continence and incontinence after radical prostatectomy be evaluated? a prospective study of patient-ratings and changes over time. J Urol. 2014;192(4):1155-61. https://doi.org/10.1016/j.juro.2014.03.113

17. Elm EV, Altman DG, Egger M, Pocock SJ, Gotzsche PC, Vandenbroucke JP. The Strengthening the Reporting of Observational Studies in Epidemiology (STROBE) Statement: guidelines for Reporting Observational Studies. PLoS Med. 2007;4(10):e296. https://doi.org/10.1016/j. jclinepi.2007.11.008

18. Wang $X$, Ji X. Sample size estimation in clinical research: from randomized controlled trials to observational studies. Chest. 2020;158(1S):S12-S20. https://doi.org/10.1016/j.chest.2020.03.010

19. Bernardes MFVG, Chagas SC, Izidoro LCR, Veloso DFM, Chianca TCM, Mata LRF. Impact of urinary incontinence on the quality of life of individuals undergoing radical prostatectomy. Rev Latino-Am Enfermagem. 2019;27:e3131. https://doi.org/10.1590/1518-8345.2757.3131

20. Schober P, Boer C, Schwarte LA. Correlation coefficients: appropriate use and interpretation. Anesth Analg. 2018;126(5):1763-68. https://doi. org/10.1213/ANE.0000000000002864

21. Cohen JA. A coefficient of agreement for nominal scales. Educ Psychol Meas. 1960;20(1):37-46. https://doi. org/10.1177/001316446002000104

22. Machioka K, Kadono Y, Naito R, Nakashima K, lijima M, Kawaguchi S, et al. Evaluating urinary incontinence before and after radical prostatectomy using the international consultation on incontinence questionnaire-short form. Neurourol Urodyn. 2019;38(2):726-33. https://doi.org/10.1002/nau.23907 
23. Kontur SC, SchAtzI G, Valimbert E, Marberger M. Differences in objective and subjective grade of incontinence after radical prostatectomy: a long term follow up study. Eur Urol Suppl. 2010;9(6):623. https://doi.org/10.1016/S1569-9056(10)61538-2

24. Trofimenko V, Myers JB, Brant WO. Post-Prostatectomy incontinence: how common and bothersome is it really? Sex Med Rev. 2017;5(4):53643. https://doi.org/10.1016/j.sxmr.2017.05.001

25. Lee SR, Kim HW, Lee JW, Jeong WJ, Rha KH, Kim JH. Discrepancies in perception of urinary incontinence between patient and physician after robotic radical prostatectomy. Yonsei Med J. 2010;51(6):883-7. https://doi.org/10.3349/ymj.2010.51.6.883

26. Malik RD, Cohn JA, Fedunok PA, Chung DE, Bales GT. Assessing variability of the 24-hour pad weight test in men with post-prostatectomy incontinence. Int Braz J Urol. 2016;42(2):327-33. https://doi.org/10.1590/S1677-5538.IBJU.2014.0506

27. Sacco E, Bientinesi R, Gandi C, Di Gianfrancesco L, Pierconti F, Racioppi M, et al. Patient pad count is a poor measure of urinary incontinence compared with 48-h pad test: results of a large-scale multicentre study. BJU Int. 2019;123(5A):E69-E78. https://doi.org/10.1111/bju.14566

28. Tan GY, Douaihy YE, Te AE, Tewari AK. Scientific and technical advances in continence recovery following radical prostatectomy. Expert Rev Med Devices. 2009;6(4):431-53. https://doi.org/10.1586/erd.09.19

29. Wallerstedt A, Carlsson S, Nilsson AE, Johansson E, Nyberg T, Steineck G, et al. Pad use and patient reported bother from urinary leakage after radical prostatectomy. J Urol. 2012;187(1):196-200. https://doi.org/10.1016/j.juro.2011.09.030

30. Holze S, Mendes M, Healy KV, Koehler N, Gansera L, Truss MC, et al. Comparison of various continence definitions in a large group of patients undergoing radical prostatectomy: a multicentre, prospective study. BMC Urol. 2019;19(1):70. https://doi.org/10.1186/s12894-019-0500-6

31. Haga N, Yanagida T, Yabe M, Akaihata H, Hata J, Sato Y, et al. Timing of urinary pad exchanges was the most important factor affecting quality of life in the early postoperative period after robot-assisted laparoscopic radical prostatectomy. J Endourol. 2015;29(9):1044-51. https://doi.org/10.1089/end.2015.0326

32. Mungovan SF, Huijbers BP, Hirschhorn AD, Patel MI. What makes men leak? an investigation of objective and self-report measures of urinary incontinence early after radical prostatectomy. Neurourol Urodyn. 2016;35(2):225-9. https://doi.org/10.1002/nau.22701

33. Soto-González M, Carrera IC, Gutiérrez Nieto M, Caeiro EML. Assessment of male urinary incontinence postprostatectomy through the Consultation on Incontinence Questionnaire-Short Form. Prog Urol. 2019;30(4):209-13. https://doi.org/10.1016/j.purol.2019.10.007

34. Smither AR, Guralnick ML, Davis NB, See WA. Quantifying the natural history of post-radical prostatectomy incontinence using objective pad test data. BMC Urol. 2007;7:2. https://doi.org/10.1186/1471-2490-7-2

35. Soto-González M, Carrera IC, Caeiro EML, Nieto MG. Circunstancias que pueden disminuir la fiabilidad de los instrumentos para valorar la incontinencia urinaria masculina. Rehabilitación (Madr). 2019;53(1):8-12. https://doi.org/10.1016/j.rh.2018.09.003 